\title{
Analysis of the impact of tourism industry on the integration of new urbanization in the tourism industry based on regression analysis
}

\author{
Zhang Junying \\ Qinghai Nationalities University,Xining 810001,China
}

\begin{abstract}
Keywords: Tourism industry; Promoting effect; Linkage effect; Influence; New town; Least square method; Economic efficiency

Abstract. Tourism industry plays a very important role in developing the regional economy. The paper mainly analyses the current domestic tourism industry linkage effect on promotion factors of domestic new town economy in details. It understands economic contribution value of capital input, the amount of labor, tourism resources, and fixed assets of service industry. These factors are analyzed in details. It finished the research on the above problems by modeling. It provides some theoretical support for maximizing the tourism industry's influence in the domestic new town's economic development. At the same time, it studies these problems by modeling method, and provides reference for the related research of tourism.
\end{abstract}

\section{Introduction}

As income level rise, tourism has become one of the common needs, people can travel to see things and landscape that his lifetime has never seen before, in order to satisfy their own life needs, and increase their knowledge. From the beauty of nature which can make people feel comfortable so that a lot of trouble will disappear like smoke. Therefore, China's tourism industry has also ushered in its own space for development; establish a new mechanism of the tourism industry development strategy becomes imminent. But we have to take into account that the current tourism industry dilemma, people's require become more and more high, and the tourism industry 's impact on the environment is also very serious, how to balance the two situations, and make better develop in tourist industry is a big problem, traditional tourism industry is no longer in line with China's sustainable development strategy, a new novel which not only good for the tourism income, but also can reduce environment pollution load from the development strategy of tourism industry is in urgent need of our creation.This paper is based on this situation, the present situation of the tourism industry from me and based on a novel strategy of tourism industry development aspects to elaborate.

With the improvement of economic level year by year, the domestic tourism industry developed rapidly. The present tourism industry has already become an important backbone of our country economic development. This paper analyzed the elements of domestic tourism industry's linkage effect on promoting urban economic level [1,2]. We hope that by reasonable allocation of elements, the new urban economic level can achieve the optimization. Firstly, this paper made a detailed description of its research methods, and introduced the use of the model and parameter selection [3]. After completing the introduction of study method is, it started analyzing mechanism factors of the tourism industry linkage effect. Finally, according to the above description and analysis, the paper analyzed the core problem in detail, and completed the study of various elements' effect on enhancing new urban economy. The research on this aspect of the problem provides theoretical support of tourism industry linkage effect on optimizing urban economic level improvement.

\section{Research methods}

At present there have been many similar papers analyzed elements of domestic tourism industry's linkage effect on promoting urban economic level. The papers analyzed this problem mainly by using the parameter analysis and non-parametric analysis [4,5]. The parameter analysis method makes model according to the characteristic and feasibility of real data, and then uses the dust to calculate 
the objective function, then finishes the relevant comparisons of actual data and production function [6]. This paper prepares to construct the model by parameter analysis method here, and do the related research on it.

\section{Introduction of the production function C-D's economic growth model}

According to different objects, parameter analysis method can produce different production functions [7]. By using parameter analysis method, the paper modified and formed the model as shown below:

$$
Y=A_{0} e^{n} X_{1}^{a 1} X_{2}^{a 2} \ldots X_{n}^{a n}
$$

Here, A0 means the relevant technical level; $r$ means technology progress rate; $t$ means period parameter; $\mathrm{Xi} \quad(i=1,2, \cdots, n)$ represent the amount of elements in early period; $a_{i}(i=1,2, \cdots, n)$ represent the output elasticity of each relevant inputs [8]. Here, if the function error settings vary in prophase, the measurement methods and the actual data will have some differences. This paper here assume that the error function in the early stage keep the same.

On production function, the value of elasticity coefficient has three kinds of situations. One is $a_{1}+a_{2}+\cdots+a_{n}>1$, the production function has certain increasing returns rate, and we can appropriately expand the production scale to improve the economic benefit. Secondly, when $a_{1}+a_{2}+\cdots+a_{n}<1$, it's no longer suitable for the expansion of the current scale [9-11]. Finally, $a_{1}+a_{2}+\cdots+a_{n}>1$, means production number already have had the constant rate of return, it need to increase technical level to further improve economic efficiency.

\section{Selection problems about parameter variables}

Tourism as the tertiary industry, it also needs some kind of outside real things in some aspects. Because that tertiary industry is a service industry, it has no actual products [12]. So it has some problems in industry evaluation. At present, most experts and scholars usually use product factor, service factor etc. as the evaluation index of related factors. By using employment number, the amount of capital investment, technology progress and tourism related resources these four elements as its parameter variables, this paper analyzed the factor contribution rate. And it established the C-D function form as shown below:

$$
Y=A_{0} e^{n} K^{\alpha} L^{\beta} R^{r}
$$

Among them, tourism income is $\mathrm{Y}$, technical progress is A0, and $\mathrm{K}$ means the investment, employment number is $\mathrm{L}$. The capital labor and capital flexible resources are $\alpha, \beta$ and $\gamma$.

According to the above function, it did the relevant calculation and got the following regression model is shown as below:

$$
\ln Y=\ln A_{0}+\alpha \ln K+\beta \ln L+\gamma \ln R
$$

And then use the least squares method to carry out the related regression analysis, so we can get the production function equation of tourism industries.

\section{Analysis of tourism industry linkage effect elements mechanism}

The current development of the domestic tertiary industry is very hot. Its profit occupies a greater part of GPD and there is a huge income as shown in Table 1. The development of the tourism industry has promoting effects on developing the regional economy to some extent. It even can be said that tourism's development can benefit a lot of industry as shown Table 2. Of course, the prosperity of the regional economy also can promote the development of local tourism industry to some extent. The 
development of tourism and economy is double win. From government's perspective, the tourism industry needs the optimization of industrial structure and incensement of capital investment. From the view of enterprises, they will find a lot of opportunities in the linkage effect of tourism industry, and then develop various resources related to tourism gradually. This will provide more external conditions for the development of tourism industry. From the perspective of residents in the region, tourism industry plays an important role in people's living standard enhancement. Based on the above statement, we can see the win-win effect brought about by the development of the tourism industry. It benefits all the people in the region.

Table 1. The total revenue and GDP

\begin{tabular}{l|l|l|l|l|l}
\hline Year & $\begin{array}{c}\text { A province } \\
\text { GDP(100 } \\
\text { million Yuan) }\end{array}$ & $\begin{array}{c}\text { Year-on-year } \\
\text { growth (\%) }\end{array}$ & $\begin{array}{c}\text { The total } \\
\text { income of } \\
\text { Tourism }\end{array}$ & $\begin{array}{c}\text { Year-on-year } \\
\text { growth (\%) }\end{array}$ & $\begin{array}{l}\text { Equivalent } \\
\text { GDP(\%) }\end{array}$ \\
\hline 2000 & 402.25 & 8.0 & 258.10 & 16.2 & 6.4 \\
2001 & 4421.76 & 10.3 & 314.00 & 21.7 & 7.1 \\
2002 & 4875.11 & 10.6 & 380.20 & 21.1 & 7.8 \\
2003 & 5456.37 & 11.9 & 420.80 & 10.7 & 7.7 \\
2004 & 6556.01 & 14.5 & 566.23 & 48.9 & 8.6 \\
2005 & 7385.11 & 12.6 & 721.26 & 27.4 & 9.8 \\
2006 & 8637.80 & 13.3 & 979.6 & 35.8 & 11.3 \\
2007 & 10505.30 & 14.2 & 1217.3 & 24.3 & 11.6 \\
2009 & 14151.30 & 14.5 & 1472.5 & 34.8 & 10.4 \\
\hline
\end{tabular}

Table 2. Inbound tourism income of each industry

\begin{tabular}{|c|c|c|c|c|c|c|c|c|}
\hline Year & \begin{tabular}{l}
\multicolumn{1}{c}{ Total } \\
US \\
\$million)
\end{tabular} & $\begin{array}{l}\quad \text { Tour } \\
\text { (US } \\
\text { \$millio } \\
\text { n) }\end{array}$ & $\begin{array}{l}\text { Catering } \\
\text { (US } \\
\text { \$million) }\end{array}$ & $\begin{array}{l}\text { Accomm } \\
\text { odation (US } \\
\text { \$million) }\end{array}$ & $\begin{array}{l}\text { Tourist } \\
\text { Straffic } \\
\text { (US } \\
\text { \$million) }\end{array}$ & $\begin{array}{l}\quad \text { Touri } \\
\mathrm{t} \text { sm } \\
\text { shoppin } \\
\mathrm{g} \quad \text { (US } \\
\text { \$millio } \\
\mathrm{n})\end{array}$ & $\begin{array}{l}\text { Entertain } \\
\text { ment (US } \\
\text { \$million) }\end{array}$ & $\begin{array}{l}\quad \text { Other } \\
\text { s } \text { (US } \\
\text { \$millio } \\
\text { n) }\end{array}$ \\
\hline 2004 & 288.85 & 13.78 & 33.32 & & 89.54 & 30.23 & 15.32 & 30.24 \\
\hline 2005 & 315.50 & 14.53 & 38.54 & 91.25 & 92.25 & 38.22 & 15.79 & 24.23 \\
\hline 2006 & 390.00 & 16.86 & 42.56 & 95.22 & 95.14 & 54.34 & 17.23 & 73.61 \\
\hline 2007 & 512.42 & 21.52 & 39.46 & 61.49 & 188.57 & $8^{102.2}$ & 18.45 & 76.86 \\
\hline 2009 & 288.56 & 13.06 & 24.76 & 38.71 & 106.62 & 59.65 & 9.45 & 36.31 \\
\hline
\end{tabular}

After reading relevant materials, this paper carried out a series of analysis according to the win-win effect, and had the mechanism model as shown in Figure 1.

We can see from the above mechanism model that, it is a full closed model. Under the stimulus of external environment, residents in the region, enterprises and government, human or capital resources and so on, the production factors' input form a link mutually influence [15]. It not only promotes the tourism income in the region, but also stimulates economic development relevant to tourism. Of course, it can also be seen that economic increase has feedback effect to certain extent. At the same time, the four elements of the tourism industry mutual promote and influence with each other to certain extent. Technology development also plays an important role in promoting the tourism industry. 
As known to us all, raise of the level of science and technology is very important for economic development. Thus increasing the level of science and technology also plays an important role in the development of the tourism industry [16]. First of all, it can further optimize the tourism industrial structure, transform the current economic growth mode, and further improve the comprehensive quality of workers. Secondly, it can make the labor efficiency be further improved on its original basis, and provide more excellent external factors for industrial development.

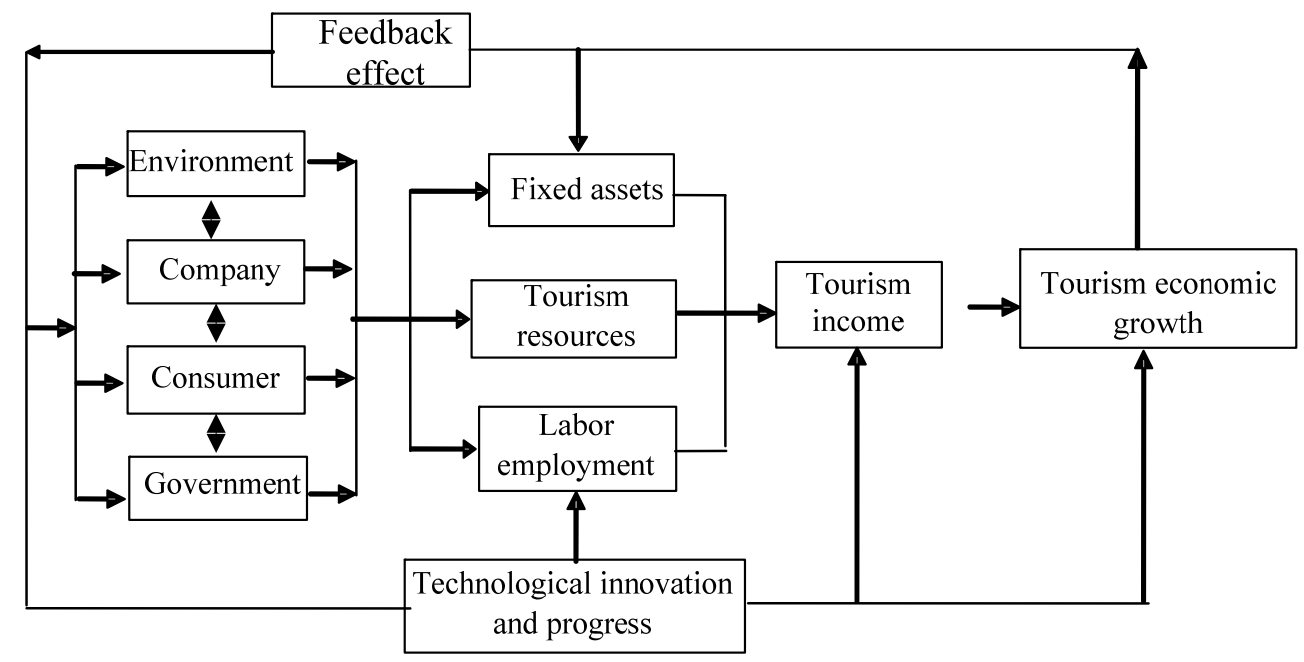

Figure 1. The mechanism model

Analysis of the contribution value of tourism industry linkage effect on improving economic level

\section{The data measurement of tourism industry linkage effect on new urban economic development}

According to the analysis of tourism production factors above, we know that when we measure tourism industry linkage effect production factors on improving the level of economy, it demands for a unified plan of many indicators such as labor. This paper chooses $Y$ and the profit of new town hotel and travel agency as new urban economic growth index. Investment index includes $\mathrm{K}$ and the fixed assets new towns hotel and travel agency. Employment labor index chooses the number of employee in new towns' similar industry L. Resource index of the tourism industry select the number of hotel R.

\section{Sources of tourism industry linkage effect on urban economic development data}

This paper selects a new town's tourism industry profit, fixed assets, the amount of labor, tourism resources from 2001 2008 as the research sample to carry out related research. In order to eliminate the influence of price fluctuations in this period, to ensure the data consistency and comparability of the result, and to obtain the fixed assets, earnings, and labor of hotel and travel agency as well as the number of hotels from external investigation and evidence, this paper uses dimensionless method to carry out a series of procession of it. The paper transforms it to related, effective, the authentic index data, which provides a source of data for the analysis of tourism industry linkage effect on new urban economic level improving.

\section{The equation output of the researching process}


Here, according to the above description, we assume that the regression equation is shown as follows:

$$
Y=C\left(C_{1}\right)+\left(C_{2}\right) t+\left(C_{3}\right) K+\left(C_{4}\right) L+\left(C_{5}\right) R
$$

And the paper use the related software to analyses new town's tourism industry data from 2001-2008 by least square method, and get the following regression equation is shown:

$$
\begin{aligned}
& Y=C+0.461884 K-0.09842 L+0.443982 R \\
& R^{2}=0.953436
\end{aligned}
$$

By the analysis of related software, the paper can get:

$$
\alpha=0.451884, \quad \beta=-0.09842, \quad \gamma=0.443982
$$

According to the above we can know, with the new urban investment growth increase $1 \%$, it can make the regional economic growth increased $0.461884 \%$. The data showed that investment plays a very important role in the development of tourism industry. The output elasticity of labor input data is -0.09842 , the data shows, on the basis of the existing labor quantity, to increase it has a negative effect on development of the tourism industry. The amount of labor of the new town's tourism industry is saturated and even too saturated. When finishing the above research, we can't forget is the key factor is technology. We must turn the industry extensive mode of economic development to technology intensive mode of economic development. At the same time, according to the current situation of the tourism industry, the contribution value and capital investment of tourism are almost the same. Here, we can see, $\alpha+\beta+\gamma<1$, so we know the improvement of the tourism industry linkage effect on urban economic level. It belongs to the industries that return decrease to scale. At the same time, it can be seen that the above equation for this problem is very appropriate.

\section{Result analysis}

Through the above data and the SPPS11.5 statistical analysis it, the contribution rate is shown in Table 3.

Table 3. New town tourism industry linkage effect factors contribution rate

\begin{tabular}{c|l|l|l|l}
\hline Year & ER & EL & EK & EA \\
\hline 2008 & -0.40652296 & 0.310614713 & 1.095296195 & 0.000612053 \\
2009 & -0.15431191 & -0.013412980 & 1.167139856 & 0.000585046 \\
2010 & -0.93167666 & 0.849601531 & 1.078770752 & 0.003304376 \\
2011 & -0.38232108 & 0.251482330 & 1.126381540 & 0.004457207 \\
2012 & -0.07497338 & 0.080441363 & 0.994449938 & 8.207490005 \\
2013 & -0.01726138 & 0.179839836 & 0.844102938 & -0.006681430 \\
2014 & -0.20274001 & -0.079357320 & 1.281192408 & 0.000904919 \\
\hline
\end{tabular}

As can be seen from the table, the contribution rate of capital input related is greater than that of the amount of labor, technology and tourism resources in these years. And tourism resources contribution rate is the smallest in the whole cities' economic growth. Through the above, it can be learned under Chinese tourism industry linkage effect, in the key elements of new urban economic level's improvement, funds occupy the important position. Advantages of the amount of labor and tourism resources will decrease with the social and economic growth. Only increase capital input, can we improve the new urban economic level next.

\section{Summary}

Tourism industry plays a very important role in developing the regional economy. Many domestic scholars have done many researches on it, but few scholars have done related analysis on elements of the tourism industry linkage effect. Based on this situation, this paper analyzed elements of domestic 
tourism industry's linkage effect on promoting urban economic level. By using the least square method, this paper made a detailed regression analysis of its elements, and finished the research on above problems based on data. This research provides certain theory support for the tourism industry's effect on maximizing the new urban economic efficiency. And also provides a new research method for same issues in other fields by regression analysis.

\section{Acknowledgments}

The work was supported by the Youth Project of National Social Science Fund with the project number 15027.

\section{References}

[1]Yong Yang, "Agglomeration density and tourism development in China: An empirical research based on dynamic panel data model", Tourism Management, Vol. 33, No. 6, pp. 1347-1359, 2012.

[2]Gregory Ashworth, Stephen J. Page, "Urban tourism research: Recent progress and current paradoxes", Tourism Management, Vol. 32, No. 1, pp. 1-15, 2011.

[3]Rhodri Thomas, Gareth Shaw, Stephen J. Page, "Understanding small firms in tourism: A perspective on research trends and challenges", Tourism Management, Vol. 32, No. 5, pp. 963-976, 2011.

[4]Shi Yong, "Research on The Wind Speed Prediction Based on Wavelet Analysis and Phase Space Reconstruction", JDCTA, Vol. 7, No. 3, pp. 112 - 118, 2013.

[5]Joanne Connell, "Film tourism - Evolution, progress and prospects", Tourism Management, Vol. 33, No. 5, pp. 1007-1029, 2012.

[6]Thomas A Hutton, "Service industries, globalization, and urban restructuring within the Asia-Pacific: new development trajectories and planning responses", Progress in Planning, Vol. 61, No. 1, pp. 1-74, 2006.

[7]Zhang Meili, Shi Chunsheng, "Research on Matching Effect of Market-oriented Organizational Innovation and Technological Innovation", JDCTA, Vol. 7, No. 1, pp. 204 -212, 2013.

[8]Rebecca Sims, "Putting place on the menu: The negotiation of locality in UK food tourism, from production to consumption", Journal of Rural Studies, Vol. 26, No. 2, pp. 105-115, 2010.

[9]Ling-Zhong Lin, Huery-Ren Yeh, "Analysis of tour values to develop enablers using an interpretive hierarchy-based model in Taiwan", Tourism Management, Vol. 34, pp. 133-144, 2013.

[10]Mark P. Hampton, Huery-Ren Yeh, "Heritage, local communities and economic development", Annals of Tourism Research, Vol. 32, No. 3, pp. 735-759, 2005.

[11]Ren Ying, "An Empirical Study of Smeeds Law Effectiveness Based on Panel Data from Major OECD Members", AISS, Vol. 5, No. 2, pp. 28 -35, 2013.

[12]Hsiaofei Chang, Feng Li, Zhengguo Li, Rusong Wang, Yanglin Wang, "Urban landscape pattern design from the viewpoint of networks: A case study of Changzhou city in Southeast China", Ecological Complexity, Vol. 8, No. 1, pp. 51-59, 2011. 